\title{
Once were young: reflexive hindsight and the problem of teen parents
}

\author{
Annelies Kamp \\ Dublin City University ${ }^{1}$ \\ and Peter Kelly \\ Edge Hill University
}

\section{Introduction - the 'problem' of teenage pregnancy and parenting}

There is an extensive body of research dating back to the 1970s that has framed discussions of teenage pregnancy and parenting in 'epidemic' terms (Luttrell 2003). Public opinion often uncritically adopts the same discourse. While there are more teenage parents because there are more teenagers - some 16 million young women aged 15-19 gave birth each year (United Nations Population Fund 2013) - rates of teenage pregnancy and parenting have steadily declined in developed Western countries during the last 30 years (Kamp 2007). While teenagers from all social classes become pregnant it is those from disadvantaged social groups who are more likely to persist with their pregnancy and become teenage parents (Luker 1996; D. Kelly 2000; Kost, Henshaw and Carlin 2010). In the UK, the likelihood of becoming pregnant and going on to parent your child is almost ten times higher for marginalized young women compared to those from families with professional backgrounds (Teenage Pregnancy Unit 2002, 2004; Colen, Geronimus and Phipps 2006).

The decline in the teenage birthrate is clearly not paralleled by a decline in concern about 'too-soon' parenting. Teenage pregnancy and parenting have been constructed as an increasingly compelling and complex policy dilemma. In what Ulrich Beck (1992) calls the risk society where a successful D-I-Y biography is something that is to be managed by making good choices, and by participation in education systems and labour markets, the dilemma of parenting while still a teenager is commonly associated with a range of disadvantages for the teenage parent, for his or her child, 'for society in general and taxpayers

\footnotetext{
${ }^{1}$ Email: annelies.kamp@dcu.ie
} 
in particular' (UNICEF 2001:3; see also Bonell 2004 and Teenage Pregnancy Unit 2004). Furthermore, neo-liberal agendas of re-privatization and the re-configuring of the welfare state have had a role to play in how teenage pregnancy and parenting are managed (Lesko 2001).

Public ‘(mis)representations' and diverse discourses - religious, medical, legal, and psychological - frame the way teenage pregnancy and parenting are understood as particular 'problems' (Luttrell 2003: 25). Teenage pregnancy and parenting have, at times, been suggested as the greatest cause of dropping out of school for teenage girls (Brindis and Philliber 1998); yet teenage parenting can also be a powerful motivating force for previously disengaged students. As this paper is prepared, one of us is following the media in Ireland where a parenting teenager, formerly disengaged from education, wishing to return to school and having been offered a place in a highly-regarded second-level school had that offer withdrawn when her status as a parent became known to the school on the basis that it was the 'duty' of the Principal 'to protect the honorable majority' of his pupils (McCarthy 2012).

For Deirdre Kelly (2000) discourses of teenage pregnancy are a 'stigma contest' between social, religious and economic conservatives and their 'wrong-family' discourse; oppositional movements such as feminism and their 'wrong-society' discourse; teenage parents' own 'stigma-is-wrong' discourse and bureaucratic experts and their dominant 'wrong-girl' discourse. This 'wrong-girl' discourse scrutinizes the motivations and choices of pregnant and parenting teenagers in ways that older women who are pregnant and parenting are never scrutinized. Feminist discourses have critiqued the focus on judging on the 'choices' of pregnant teenagers, arguing that rational choice-making is always constrained both materially and by cultural meanings associated with sexuality and motherhood (Petchesky 1984). 
These competing discourses that shape our understanding of teen pregnancy and parenting position the subject in an already constituted category (teenage parents), a category that is almost universally considered to be negative, non-adult, and which evidences the inability of certain young people to 'appropriately' govern their own desires and behavior. These discourses, their limits and possibilities, the things that are able to be said, or not, about teenage pregnancy and parenting, the persons who can speak, who can manage this problem, and those who can't, become part of the self-making of young parents themselves. These discourses attempt to establish that these young people, as evidenced by their state, are unable to participate in the world as autonomous, choice-making adults. This position/state enables an array of adult expertise and institutions to intervene into, and make judgments about their lives, their choices and the future prospects of both them and their children.

Against this background we want to suggest that adults are the ones who do the social science that takes young people as its object - in whatever form, in relation to whatever issue or problem. As a consequence adult social scientists, who once were young, are continually confronted with the dilemma of 'what mode is appropriate for giving form to thinking' when we take young people as our object (Rabinow 2009: 27-8). In this paper we draw on social theory, our background in Youth Studies and, for one of us, experiential knowledge as a former teenage parent, to trouble and unsettle the social science that engages with the problem of teenage pregnancy and parenting. Our intent here is to work with this particular 'problem' as a mechanism to consider the methodological possibilities of reflexive hindsight in the social sciences. In terms that owe much to the work of Michel Foucault, and his legacy, we seek to explore an ethos, a disposition to the conduct of what might be called a 'critical social science' or 'critical Youth Studies' (Fine 2008; Giroux 2012), as we take young people in general, and teenage parents in particular, as our objects. Foucault (2007a: 118) described this ethos as a critical ontology of ourselves: a form of critique which is 'at one and the same 
time the historical analysis of the limits that are imposed on us and an experiment with the possibility of going beyond them'. This ethos provides no ultimate resolution to the dilemmas of adults doing social science on/with/for/about young people; 'the theoretical and practical experience we have of our limits and of the possibility of moving beyond them is always limited and determined' (Foucault 2007a: 118).

The paper explores what it might mean to work at/on the limits of reflexive hindsight, and engages with the problem of looking back — the possibilities and limits of judgment, memory, imagination, sentimentality, romanticising, forgetting. To do this we construct a conversation where we identify ourselves as individual authors of different parts, departing from a more traditional, linear account. While we highlight teenage parenting as a particular example, the multivocality of the paper serves to underscore the broader methodological argument. We create a warrant for this approach in what follows.

\section{Reflexive hindsight: we once were young}

What sense can be made of a problem such as teen pregnancy and parenting? What positions are available to us as we do the social science that might take this problem as its object? We share a general concern with exploring the spaces, the positions, the judgments and forms of address that are available to us as adult social scientists who are interested, in various ways, with doing Youth Studies. More particularly we, as individuals, come to these discussions from a number of different positions and with a variety of interests. Some of these have a more recent history. Some, possibly more evocative and powerful, come from when once we were young.

\section{Annelies:}

It is the end of a long, happy Sunday in Dublin. We - my daughter, son-in-law, grand-children and their extended family — have spent the day in my apartment sharing High Tea on the occasion of my daughter's $35^{\text {th }}$ birthday. In the evening, 
after they have headed home and before I commence the dishwashing, I pour myself a solitary glass of wine and toast my teenage parent self, 35 years on.

This moment of reflection was not orchestrated; it had occurred unbidden in that suddenly quiet moment at the end of a special day. Day by day my daughter and I have moved forward from her birth in New Zealand when I was 16; we have quietly accumulated 35 years of walking through our lives together. This thought brings me such joy; this thought would bring any first-time parent such joy. I smile, draw the Sunday papers closer: a quick scan before I begin the clean up. And this is what I read:

I once saw a teenage mother on the bus teaching her toddler how to say the Fword. She found it hilarious, as if she were training a parrot. I was shocked. The poor child was being robbed of his innocence at least a decade too soon, and at the hands of his own mother. (Smith 2011:11)

The article, by philosopher Robert Rowland Smith, was concerned with whether swearing is wrong. He opines that sometimes swearing is okay; it is the means by which we 'convert a mere word into a real thing, something more adequate for the occasion'. But as I sat there with my glass of wine I struggled with why he felt the need to commence his philosophical discussion on swearing by taking the time to label a less-than-ideal mother as 'a teenage mother'. What did the age of this particular mother have to do with anything? As a philosopher, I would have hoped he would know better than to contribute to that particular discourse. At the same time, I would have thought that 35 years on I would have developed a thicker skin to this discourse.

Back then, my working-class parents, post-WWII European immigrants to New Zealand had 'made it' to the middle-classes and had strong community networks that supported all of us in the transition of my daughter joining our family. I did, over 
time, complete my secondary schooling, but not in the public gaze. Our familial response to my pregnancy was to hide my pregnant-self from my former school. I can't say my school would not have supported me if I had declared that I was now a parenting student: it never occurred to us to ask. Teenage pregnancy and parenting in the 1970s was a negative space, and withdrawal was what one did.

One of the experiences of that time that has prompted my continuing interest in the experiences of teenage parents happened shortly after my last minute choice to become a teenage parent. I struggle with that word 'choice': is not making a decision a 'choice'? The denial and ambivalence that surrounded the issues of first-boyfriend teenage sex. The possibility of maybe being pregnant. The eventual appointment with an anonymous Doctor (me in school uniform). The doing-nothing with knowing I am pregnant and becoming more pregnant and my clothes will not hide this forever. The day I finally summon the courage to utter the word 'pregnant' to my parents. The 'We'll get through this together' of my family (but what is this 'this' that we will get through?). The daily going off to school. Seemingly, nothing changes. Nothing happens as this baby will be adopted, will become someone else's baby. The school year finishes and exams are sat and still no-one knows. Four months later and a daughter is born. And three days later in a moment of ambivalence, needing to know she will be safe, I decide to keep her.

When my daughter was six weeks old I took her back to the doctor who had attended her birth for a check-up. He was not our family doctor but a specialist. I remember walking into his surgery, holding this tiny baby girl swaddled in a blue cocoon. When last he' $\mathrm{d}$ seen me, at the birth, 'baby X' was to be adopted. I remember his curt disbelief when he saw my daughter was with me. I recall, and still feel, his asking me why I had 'that child' with me; his blunt assertion that I had ruined my life and, 
probably, her life. At that point, riddled with the insecurities that all new parents encounter, his words nearly crushed me. Many times in the intervening years I have recalled that moment and the impact of that particular discourse, one that framed my decision to compound the mistake of being a pregnant teenager with the even more damaging mistake of becoming a teenage parent in fixed, overtly negative, ways. Years later I would wish he could see the person my daughter had become, as far from a ruin as it is possible to be. I commenced my doctoral research confident in having proven him wrong: both of us had thrived. That research brought me into close engagement with what social science tells us about teenage parents and their life patterns and I developed a different narrative of my life. I had suffered marital instability. I did struggle to continue with my education. I did earn far less than I would have if I'd made different 'choices'. My victory narrative was now muted. I had found myself in the social science literature and these discourses demonstrated that I had indeed conformed with the anticipated (that is, apparently lesser) trajectories for those who parent-too-soon.

The understandings generated by traditional social science about teenage pregnancy and parenting do sometimes resonate with my embodied knowledge, but only in partial ways. The ways we come to know are always in some way limited but those limitations become troubled, allowing a reframing of our knowing. Thinking back, the emotionality — not only the burning fears and doubts but also the feelings of redemption that becoming a parent provided — was rarely evident in what the literature told me of the lives of teenage parents. With hindsight, I have come to understand that first parenting experience - that supposedly ruinous journey - as one surrounded by a strong, loving family, full of naivety and happiness. In contrast, my second parenting experience which occurred ten years later, in the context of maturity and marriage, was so much more traumatic. This contrast simply serves to illustrate 
that the kinds of events that the social sciences seek to explore and understand are rarely simple, never static and demand knowledge practices which accommodate that complexity and the possibilities that reside within complexity.

\section{Peter:}

In a 2011 article (Kelly 2011a) I discussed the ways in which Australian writer Tim Winton's recent novel Breath (2008) could be read as an allegorical tale about the horrors of being ordinary, and of the teenage years as being a time in life when some young people sought out, or stumbled into, situations and behaviours that, in their riskiness and danger, promised to make their lives less ordinary. I suggested that part of the power of Winton's narrative was that it is a story told from the vantage point of middle-age. From this standpoint — hindsight — we can selectively review a life and identify and locate missed opportunities, successes, failings, thwarted ambitions, unrealised dreams. At the end of the story Winton's principal character, the middle-aged Bruce Pike (Pikelet), reflects on a life marked by personal loss, a broken marriage, physical and mental breakdown, and yet some sort of parlous redemption:

I didn't exactly pull myself together...but bits of me did come around again, as flies or memories or subatomic particles will for reasons of their own. Bit by bit I congregated... and then somehow I cohered. I went on and had another life.

(Winton, 2008: 211)

My discussion of the possibilities that the position of hindsight offers was situated in relation to a project that colleagues and I had been working on that was concerned with the cultural drivers of young people's low, medium and high risk use of alcohol. In the discussions about the ontological politics (Law 2004) that shaped our research our own youth, our own memories, were an explicit, but often, also, unspoken dimension of our discussions about culture, young people and alcohol. We enacted and told stories about our experiences growing up with alcohol, the drinking, the parties, the fun, the intense 
sociability, the stupid things we did, the risks, the almost complete lack of focus on future consequences or possibilities.

Winton's use of hindsight, of memory, provides Bruce Pike with the opportunity to reflect on and reconstruct a past with a certain worldliness, an insightfulness, a sense of possibilities - lost and taken. As a technique that enables Breath to work as allegory, I suggested that hindsight provides us with a vantage point that we don't possess in the now, in the moments when we choose, embrace, stumble upon things that may be far reaching in consequence and significance — when we are young and/or old. Yet, when we and others do Youth Studies we often do so in ways that suggest that current generations of young people ought have developed a risk aware, prudent, responsible disposition to present behaviours and future consequences. Ought to be able, with foresight, to imagine and colonise their futures in ways that can guard against damage, hurt and pain. To, in effect, dis-enchant their presents and futures and render them amenable to calculation, guided by expertise.

It was in the (conversational) spaces at the intersection of our different experiences, our intellectual practice, and the benefits provided by the position of hindsight that we began to give a particular form to our thinking about the limits and possibilities of the knowledge practices that shape the way we could imagine doing Youth Studies/social science. In particular how could a particular standpoint — a reflexive hindsight shaped by experience, intellectual training and the limits and possibilities of memory, of forgetting, of self censorship and revelation — contribute to our practice?

\section{Youth studies as adult social science}

Peter:

In various spaces I have argued that Youth Studies is a diverse, far from harmonious or homogeneous discursive terrain populated by psychologists, sociologists, cultural 
theorists, criminologists, educational theorists, feminists, postmodernists, poststructuralists. The institutionalized intellectuality embodied in Youth Studies expertise travels across and constitutes this domain for a variety of purposes, professed and implied. Expertise in Youth Studies takes youth as its object - a simple enough statement. Youth is problematized in the service of empowerment and emancipation, variously understood. Youth are made knowable so that they might be educated — differently, better, to the same level as normal Youth. Youth is researched so that their desires, motivations, identities, subjectivities, intelligence, performance, resiliency, delinquency and/or aggression might be identified, noted, calculated, measured. All in the service of ends as diverse as increased school retention rates (Simmons and Thompson 2011); smoother transitions between school and work (Kelly, McGuinness and O’Connell 2012); safer sex practices (Hillier and Harrison 2007); less alcohol and drug use (Johnson 2013); increased employability (Winterton and Irwin 2012) ; and the avoidance, management or minimization of risk (Rimmer 2012). In these accounts I have developed an argument that Youth is an artefact of expertise, constructed at the intersection of a wide range of knowledges about Youth and so-called Youth issues. I have suggested that how we imagine these intersections produces our understandings of Youth. These understandings have consequences — material, symbolic and for a sense of self — in the lives of young people. As an artefact of expertise, Youth is principally about becoming: becoming an adult, a citizen, independent, responsible. There is some sense in which all constructions of Youth defer to this narrative of becoming, of transition. Moreover, there is a sense in which becoming automatically invokes the future (Kelly 2000, 2007, 2011b). 
Our aim here is not to suggest or claim that institutionalised Youth Studies/social science has little or no value. Or to suggest that Youth Studies should only do certain work in particular ways. Rather, our intent is to explore the ways in which we can trouble or unsettle the various ways in which we, and others, can think about and do Youth Studies. The work of John Law provides one means to frame this unsettling. In his After Method Law (2004: 2-4) seeks to trouble the boundaries, the limits and possibilities of institutionalised social scientific knowledge practices. In this work Law stresses that conventional ways of doing social science can produce knowledge, outcomes and consequences that can support certain truth claims and make significant contributions to human knowledge and understandings of important issues. However, if, as Law suggests, so much of the natural, the social and the cultural is 'vague, diffuse or unspecific, slippery, emotional, ephemeral, elusive or indistinct', then can the institutionalized, even standardized, rule-bound knowledge practices of the social sciences enact understandings that can account for these realities? Or do we need to 'teach ourselves to know some of the realities of the world using methods unusual to or unknown in social science'.

In his initial engagement with this question Law discusses some possibilities: 'knowing as embodiment' where we come to know 'through the hungers, tastes, discomfort, or pains of our bodies'. Knowing as 'emotionality or apprehension' would bring into view the 'worlds of sensibilities, passions, intuitions, fears and betrayals'. We might consider 'how far whatever it is that we know travels and whether it still makes sense in other locations and if so how'; this would be 'knowing as situated inquiry'. Law argues that we need to think about and embrace the sense that our ways of knowing — despite our desires to present them in terms of validity, certainty and rigour — are, indeed, imprecise and that, therefore, we need to 'find ways of knowing the indistinct and the slippery without trying to 
grasp and hold them tight. Here knowing would become possible through techniques of deliberate imprecision'.

Law's work is not unique, but it does provide a generative vocabulary for capturing and locating much of what interests us in thinking about knowledge practices. A key ordering concept is his idea of method assemblage (Law 2004: 144). He suggests that method assemblage is a process of crafting and enacting boundaries between presence, manifest absence and Otherness. Any set of knowledge practices, any methodology 'makes something present by making absence'. The concept of method assemblage tries to make explicit and imagine the consequences of a particular 'crafting, bundling, or gathering of relations' between these elements. The challenge, as we imagine it, is to identify, to unsettle what is excluded, impossible, absent when, for example, we consider and enact the problem of the teenage parent. What role or place is to be allocated or found for sexuality, for desire, for globalised education systems and labour markets, for emotional commitments, understandings and ideals of family, of choice, of the future? Where is the 'successful' teenage parent? What, then, is present? What is absent? Who/what makes such choices? What might be the consequences (intended or otherwise) of such choices?

It is in this context that the recent work of Zygmunt Bauman makes a provocative contribution to what might be called the re-enchantment of a social scientific imagination. Here, the character of this work can only be briefly sketched but turns on an interest in the ways in which individual biographies and histories are structured by social forces, and 'in particular how men and women are brought face to face with contradictions in their own lives that are utterly beyond personal and biographical resolution' (see Tester 2004: 6-10). Being pregnant at 15 , for example, is at one level, only a biological fact, a state. At so many other levels, in so many other ways, such a state is itself pregnant with ambiguity, ambivalence, uncertainty and contradiction. Related to this mission and these problems is the sort of 
political action that is informed by a sociological imagination that takes this form. As Tester suggests, Bauman's work has most often taken a course that seeks to unsettle the many intellectual, business and governmental projects which assume or presume that the 'world is clear to the understanding (or can be made clear as soon as the 'correct' method is discovered or as soon as the obstacles to clarity are got out of the way)'. Bauman's embrace of the possibilities and problems of ambivalence, and recognition of the all too human tendency to seek to impose order on this ambivalence, provokes what Tester identifies as his ethical commitment to 'attend to those who are made to suffer most sharply from the ambivalence of the human condition'.

In encountering dominant understandings of teen parenting, in examining the ways in which a range of experts, agencies, educators, politicians, commentators claim some authority to critique, judge and intervene, in trying to understand the lives that are shaped in the present and the future as a consequence of decisions taken and choices made (or not) in the face of such interventions, we are brought face to face with the limits imposed and the possibilities enacted by the ambivalence of teen parenting and of the many attempts to exterminate this ambivalence (Bauman 1990).

\section{Beyond judgment: how have we become what we are?}

It was in the third year of my research, and Grace asked if I would play 'a pregnant girl at the clinic.'. . . I grabbed the props (a hospital robe and a magazine) and sat impatiently jiggling my leg as if I had been waiting a long time to be seen. Shantae, who was playing the nurse, walked up with her clipboard and gruffly announced my name, 'Wendy Luttrell.' I stood up, feeling a bit shaken hearing my name called out so publicly and in such an authoritative tone. We moved to a space set up with a long table and two chairs. The 'nurse' ordered me to lie down and roll up my sleeve. She forcefully pulled at my arm and tightly wrapped the make believe blood pressure rope around it until it pinched. Before I could even say, 'Stop - that hurts,' the 'nurse' said, 'It has to be tight for it to work.' Then, without missing a beat, she started firing off the standard series of questions about sexual conduct. 'How many times have you 
had sex? You haven't been using protection have you? How many men have you been with anyway? You probably can't count how many.' (Luttrell 2003: 120) Luttrell (2003) poses the question of what might be possible if one could turn questions of 'judgment' about teenage parents into questions of interest about their sense of self and identity-making. For us, this in turn speaks to the question of the limits and possibilities that shape the work that we might do as researchers and educators, and how we might trouble or unsettle these. Many of our conversations about the issues we are exploring here have been framed, intellectually, by the work of Michel Foucault. Of particular interest is Foucault's (2007a, 2007b) apparent Enlightenment turn in a series of essays that he wrote towards the end of his life. In her examination of the ways in which Foucault's essays on critique and enlightenment provoke different ways of thinking about what it is that we do when, as part of our intellectual practice, we engage in critique, Judith Butler (2002: 218) argues that Foucault's account(ing) of/for enlightenment is 'one that no "Enlightenment" thinker would accept'. But this refusal does not, she argues, 'invalidate' the sort of characterization that Foucault develops. As Butler suggests it is "precisely what remains "unthought"' within the terms of enlightenment that Foucault tries to identify and describe. The key claim that Butler explores is that Foucault's provocations open up a space in which it is possible to think of critique as being less about judgment, and more about a process of de-subjugation in which we, the subjects who do critique, refuse, by degree, to be governed in such and such a way, in relation to such and such ends.

It is in this sense that Foucault (2007b: 118) suggests that enlightenment can be considered as an ethos. For Foucault, enlightenment, as a 'critical ontology of ourselves' should not be imagined as a 'theory, a doctrine, nor even as a permanent body of knowledge that is accumulating'. Rather, enlightenment should be 'conceived as an attitude, an ethos, a philosophical life in which the critique of what we are is at one and the same time the historical analysis of the limits that are imposed on us and an experiment with the possibility 
of going beyond them.' This ethos would mean that we 'try to proceed with the analysis of ourselves as beings who are historically determined, to a certain extent, by the Enlightenment', but in doing so we would seek to examine how our present conditions the limits and possibilities of our knowing and acting? How might we trouble those limits? How might we imagine the doing of social science in ways that embrace the ambivalence of the human condition?

As Foucault (2007a: 113, original emphasis) imagines it, this ethos can be understood as a 'limit attitude'. Indeed, criticism consists of 'analyzing and reflecting upon limits'. In Butler's (2002: 212-213) essay on Foucault's mode of critique, originally presented as the 2000 Raymond Williams lecture at Cambridge University, she makes reference to a concern expressed by Williams that the notion of "criticism has been unduly restricted to the notion of "fault-finding"'. Butler suggests that what Williams called for was a more limited, specific form of critique that did not "generalize too quickly: "what always needs to be understood," he wrote, "is the specificity of the response, which is not a judgment, but a practice"". For Butler this explicit use of a vocabulary that incorporates concerns with practice, specificity and judgment opens up or maps out similar spaces to Foucault. There is a positive dimension to critique as Foucault (2007a:113) imagines it: 'The point . . . is to transform the critique conducted in the form of necessary limitation into a practical critique that takes the form of a possible transgression'. More specifically critique seeks to imagine 'in what is given to us as universal, necessary, obligatory, what place is occupied by whatever is singular, contingent, and the product of arbitrary constraints?'

The troubling part of Foucault's ethos is captured in the ways in which he imagines what would make critique genealogical. Critique, in this form, "will not deduce from the form of what we are what it is impossible for us to do and know'; it 'will separate out ... the possibility of no longer being, doing or thinking what we are, do, or think' (Foucault 2007a: 
114). Critique understood in this way would make problematic both the ways in which we imagine and conduct ourselves in relation to such things as researching the problem of teenage pregnancy and parenting, and how we imagine personhood, its formation, its practice. As Butler (2002: 220-221) argues, the purchase of Foucault's position becomes apparent when we ask questions such as: 'Who can we become in such a world where the meanings and limits of the subject are set out in advance for us? By what means are we constrained as we begin to ask what we may become?' ;in considering 'what happens when we begin to become that for which there is no place in the given regime of truth?'

\section{Reflexive hindsight: a space of/for ambivalence in Youth Studies?}

In this final section we try to write some of this ambivalence into being. What would inopportune, untimely thinking from the perspective of reflexive hindsight look like? What might this mode of thinking contribute to the ways in which adult social scientists, who once were young, do Youth Studies? If we allow some space for what we have been calling reflexive hindsight in the ways in which we think about doing the social science that takes young people, including young people who are teenage parents, as its objects, then how might this position, this standpoint trouble the limits of what we have come to know and enact as social science?

In the context of her ethnographic engagement with black teen mothers in the US Wendy Luttrell (2003: 161-164) writes vividly of the epistemological tensions that are embedded in ethnographic ways of knowing. In writing about the ambivalence she felt and experienced between the scholarly demand for analytic distance, and her emotional engagement with the lives of her research participants, Luttrell describes who how she often felt 'split at her roots'. This ambivalence, she suggests, is irresolvable. In the vocabulary we have been developing here this challenge is about how we are prepared, or equipped, or inclined to engage with the limits, the possibilities, the ambivalences of what we have 
become, as we engage with the limits, the possibilities, the ambivalences of the young lives we encounter and then enact in the process and the products of our research. What, for example, should we, can we, do we make of a story like Tara's whose father died in a car accident while she was a child, and whose mother has recently died from cancer?

Anyway, if my mother was alive I wouldn't be having the baby. You know, how when a family member dies and you get pregnant as a way to deal with it? My mother died in November and I got pregnant in November so I needed to keep the baby [it is April]. I always wanted to have a baby, but not so soon, and since my mother isn't alive I went ahead and decided to have it. You know she [her mother] told me not to cry at her funeral, so I didn't cry. (cited in Luttrell 2003: 56-57)

We are not claiming that reflexive hindsight provides us/anyone with a privileged position from which to make sense of Tara's story (or anything, for that matter). Rather, we suggest that reflexive hindsight is a tool with which adult social scientists who do Youth Studies might unsettle who it is that we have become as we do Youth Studies. As adult researchers, trained in our craft, there are both limits and possibilities within the generative space that occurs in the tension between analytical detachment and emotional participation. In the past three decades, this question of reflexivity has been taken up in different ways, in different spaces, for different purposes by educational theorists, feminists, post structuralists, geographers, and queer theorists in the social sciences more broadly, and in different parts of the field of Youth Studies more particularly (Bourdieu \& Wacquant 1992; Jones 2003; Philo 2003). At this time we want to locate our concerns in the experiences of one of us for whom the problem of teenage pregnancy and parenting is experienced from the inside, a standpoint that offers the possibility of reflexive hindsight and, to some extent, the possibility of an unmarginalized 'teenage voice', that resides in the emotionality, the embodiment, and the intellectual engagement with what it feels like to have been the problem.

\section{Annelies:}


In the years subsequent to my doctoral studies I spent some time lecturing to second and third year undergraduate students in Youth, Culture and Social Change. In one of our modules we focused on Gender, Sex and Sexuality, spending some time to consider teenage parents as a 'flash point' of community concerns about teenage sexuality. I was struck each year by the reaction of students when I would 'declare' my status as a teenage parent, one who had been 'rendered decent' by the passage of time but was still — and would forever more be - 16 years older than my daughter. It was a large class, a lecture delivered in a tiered theatre and a moment of stillness would ensue as the students, many from privileged backgrounds, thought about the ambiguity of my hybrid status: 'dropout' and 'Dr' and 'lecturer' and 'teenage parent'. As a group, we would be brought face-to-face with Butler's (2002) questions that can often only be answered with the benefit of hindsight: 'Who can a teenage parent become in a world where the meanings and limits of teenage parents are set out in advance? By what means are teenage parents constrained as they began to ask what I might become?'

My memories of those early years when my age made my status as a mother problematic are undoubtedly partial. Looking back will always be incomplete: sometimes forgotten, sometimes censored. In a series of conversations about the possibilities and limitations of 'remembering' we have discussed my censoring of parts of the story shared in this paper, my struggle with disclosing what seem to be significant memories because, in the telling, they also tell partial stories of others about whom I care. As such, we fully accept the limits of what can be remembered, of what can be - or will be — told. Yet our remembering — complete with our at times deliberate forgetting - offers more in pursuit of a certain ethos than a refusal to acknowledge there is any story at all, any thinking to be done about the possibilities 
offered by our different identifications with the young people we now take as our object. Whether or not I choose to acknowledge it, reflexive hindsight informs my thinking about the problem of teenage pregnancy and parenting in the same way that my thinking about the teenage pregnancy and parenting informs my understanding of myself as a former teenage parent.

Citing the work of Annie Rogers and her colleagues, Luttrell (2003: 163, our emphasis) highlights the partial nature of any account that we can produce of our lives: 'what is said and what remains unsaid and perhaps unsayable depends on what can be held in memory and reimagined as a story to tell, which further depends upon the listener's moment by moment responses' to stories such as Tara's. Those responses can be honed by a willingness to reembody our own human experiences of acute childhood loss, or risky alcohol use, or making a decision to become a parent. At the same time, Luttrell notes that what she could know about the young women in her research was dependent on their capacity to tell their story, fragments of their story, at any given time. In a related observation Mann suggests that young people's lives are 'not remembered in tranquility in the calm waters of late maturity but described in the full flood of experience, riding the rapids of tumultuous feelings' (cited Luttrell 2003: 148). Mann's hope for the calm waters of late maturity would seem to suggest that reflexive hindsight is a tranquil space from which to construct a clear, coherent, truthful account of a life. We don't necessarily subscribe to such a view. Valerie Walkerdine's (1997) Daddy's Girl is an example of a deeply personal, often painful, revisiting of her childhood experiences and/or memories of these in making sense of her academic work. Late maturity does not have to be any more or less an ambivalent space than the teenage years. Or any time in between.

In her contribution to a collection canvassing the methodological issues related to doing critical Youth Studies, Knopp Biklen (2007) cautions adults who do ethnographies of 
young people about the troubles they may find on their trips down 'memory lane'. Yet for us, a reflexive hindsight offers a particular intervention into the knowledge practices of the social sciences that makes explicit the ambivalence and ambiguity, even irony of adult social scientists — who once were young — taking the behaviors and dispositions, the hopes, fears and aspirations, of young people as their objects. This form of intellectual practice attempts to embody the ethos that Foucault sketched, one that compels us to imagine how it is that we have become who we are despite who we were once 'destined' to be; to think about the limits and possibilities of what it is that we are/do when we call ourselves social scientists. A point to stress here is that we do not offer a programmatic guide of 'how to do Youth Studies' (in all of its diversity and plurality). That would be contradictory to what we have discussed here. And, we are not saying that what we offer is unique and/or dependent on subjective experience. Our engagements with Foucault, Bauman, Butler and, in a more explicit way, with Wendy Luttrell's sense of being split at the roots do, however, suggest what Deleuze \& Guattari (1987) might call 'lines of flight' as we work at the limits and possibilities of doing Youth Studies. As a mode of giving form to thinking reflexive hindsight challenges us in at least two ways. The first is to explore ways of thinking, writing and doing social research that works with ambivalence rather than seeking to exterminate it. The second is that this line of flight opens a space to speak back to the many assumptions, presumptions and prejudices that attach too readily to young people, particularly those who potentially suffer most sharply from the ambivalence of the human condition. 


\section{References}

Bauman, Z. 1990. Modernity and Ambivalence. Cambridge: Polity.

Beck, U. 1992. Risk Society. Towards a New Modernity. Theory, Culture \& Society. London: Sage.

Bonell, C. 2004. Why is teenage pregnancy conceptualised as a social problem? A review of quantitative research from the USA and UK. Culture, Health and Sexuality, 6, 255272.

Bourdieu, P. \& Wacquant, L. 1992. An Invitation to Reflexive Sociology. Cambridge: Polity Press.

Brindis, C. \& Philliber, S. 1998. Room to grow. Improving services for pregnant and parenting teenagers in school settings. Education and Urban Society, 30, 242 - 60.

Butler, J., 2002. What is Critique? An Essay on Foucault's Virtue. In D. Ingram (ed.) The Political: Blackwell Readings in Continental Philosophy. Oxford, MA: Blackwell Publishers, 212-28.

Colen, C., Geronimus, A.T. \& Phipps, M.G. 2006. Getting a piece of the pie? The economic boom of the 1990s and declining teen birth rates in the United States. Social Science \& Medicine, 63, 1531-1545.

Deleuze, G. \& Guattari, F. 1987. A Thousand Plateaus. Capitalizm and Schizophrenia. Minneapolis: University of Minnesota Press.

Fine, M. 2008. 'An Epilogue, of Sorts'. In J. Cammarota and M. Fine (ed.), Revolutionizing Education: Youth Participatory Action Research in Motion, pp. 213-34. New York: Routledge.

Foucault, M. 2007a. What is Critique. In S. Lotringer (ed.) The Politics of Truth. Los Angeles, CA: Semiotext(e), 41-82.

Foucault, M. 2007b. What is Enlightenment? In S. Lotringer (ed.) The Politics of Truth. Los Angeles CA: Semiotext(e), 97-120.

Giroux, H. 2012. Disposable Youth. New York: Routledge.

Hillier, L. \& Harrison, L. 2007. Building realities less limited than their own: young people practicing same sex attraction on the internet. Sexualities: Studies in Culture and Society, 10, 1, 82-100.

Johnson, P. 2013. 'You think you're a revel on a big bottle': teenage drinking, peers and performance authenticity. Journal of Youth Studies, 16, 6, 747-58.

Jones, O. 2003. 'Endlessly Revisited and Forever Gone': On Memory, Reverie and Emotional Imagination in Doing Children's Geographies. An 'Addendum' to “"To Go Back up the Side Hill": Memories, Imaginations and Reveries of Childhood' by Chris Philo. Children's Geographies, 1, 1, 25-36.

Kamp, A. 2007. Policy hysteria in practice: Teenage parents at secondary school in Australia. In J. Mcleod \& A. Allard (eds.) Learning from the Margins: Young Women, Social Exclusion and Education. London: Routledge, 95-107.

Kelly, D.M. 2000. Pregnant with Meaning. Teen Mothers and the Politics of Inclusive Schooling. New York: Peter Lang.

Kelly, E. \& McGuinness, S. \& O'Connell, P.J. 2012. Transitions to long-term unemployment risk among young people: evidence from Ireland. Journal of Youth Studies, 15, 6, 780-801.

Kelly, P. 2000. Youth as an Artefact of Expertise: Problematising the Practise of Youth Studies. Journal of Youth Studies, 3, 301-15.

Kelly, P. 2007. Governing Individualized Risk Biographies: New Class Intellectuals and the Problem of Youth at-Risk. British Journal of Sociology of Education, 28, 39-53.

Kelly, P. 2011a. Breath and The Truths of Youth At-Risk: Allegory and the Social Scientific Imagination. Journal of Youth Studies, 14, 431-47. 
Kelly, P. 2011b. An Untimely Future for Youth Studies? Australian Journal of Youth Studies, 30, 47-53.

Knopp Bilken, S. 2007. Trouble on Memory Lane: Adults and Self-Retrospection in Researching Youth. In A. Best (ed.) Representing Youth: Methodological Issues in Critical Youth Studies. New York: New York University Press, 251-68.

Kost, K., Henshaw, S. \& Carlin, L. 2010. US Teenage Pregnancies, Births and Abortions: National and State Trends by Race and Ethnicity.

Law, J. 2004. After Method: Mess in Social Science Research. London: Routledge.

Lesko, N. 2001. Act your Age! A Cultural Construction of Adolescence. New York: Routledge Falmer.

Luker, K. 1996. Dubious Conceptions: The Politics of Teenage Pregnancy. Cambridge, MA: Harvard University Press.

Luttrell, W. 2003. Pregnant Bodies, Fertile Minds: Gender, Race, and the Schooling of Pregnant Teens. New York: Routledge.

McCarthy, J. 2012. School 'isn't for pregnant girls' The Sunday Times, 29 April, p. 1.

Petchesky, R. 1984. Abortion and Women's Choice: The State, Sexuality and Reproductive Freedom. New York: Longman.

Philo, C. 2003. "To Go Back up the Side Hill": Memories, Imaginations and Reveries of Childhood. Children's Geographies, 1, 1, 7-24.

Rabinow, P. 2009. Foucault's untimely struggle: Toward a form of spirituality. Theory, Culture \& Society, 26, 25-44.

Rimmer, M. 2012. The participation and decision making of 'at risk' youth in community music projects: an exploration of three case studies. Journal of Youth Studies, 15, 3 , 329-350.

Simmons, R. \& Thompson, R. 2011. NEET Young People and Training for Work: Learning on the Margins. Stoke-on-Trent: Trentham Books Ltd.

Smith, R., 2011. To be nor not to be. The Sunday Times Magazine. Dublin: The Sunday Times, 1.

Teenage Pregnancy Unit. 2002. Teenage Pregnancy and Neighbourhood Renewal: Learning from the New Deal for Communities. London: Department of Health.

Teenage Pregnancy Unit. 2004. Long Term Consequences of Teenage Births for Parents and Their Children. London: Department of Health

Tester, K. 2004. The Social Thought of Zygmunt Bauman. Palgrave: Basingstoke.

UNICEF. 2001. A League Table of Teenage Births in Rich Countries. Florence: UNICEF.

United Nations Population Fund. 2013. World Population Day 2013 Statement. Accessed September 23.

http://www.unfpa.org/public/home/news/pid/14426http://www.unfpa.org/public/home/new s/pid/14426

Walkerdine, V., 1997. Daddy's Girl: Young Girls and Popular Culture. Basingstoke: Macmillan Press.

Winterton, M. \& Irwin, S. 2012. Teenage expectations of going to university: the ebb and flow of influences from 14 to 18. Journal of Youth Studies, 15, 7, 858-874.

Winton, T. 2008. Breath. London: Picador. 